\title{
Interference with protease-activated receptor 1 does not reduce damage to subventricular zone cells of immature rodent brain following exposure to blood or blood plasma
}

\author{
Xiaoyan Mao and Marc R Del Bigio*
}

\begin{abstract}
Background: Prior work showed that whole blood, plasma, and serum injections are damaging to the neonatal rodent brain in a model of intracerebral/periventricular hemorrhage. Thrombin alone is also damaging. In adult animal models of hemorrhagic stroke, the protease-activated (thrombin) receptor PAR1 mediates some of the brain damage. We hypothesized that PAR1 interference will reduce the adverse effects of blood products on immature rodent brain and cells.

Results: Cultured oligodendrocyte precursor cells from rats and mice were exposed to blood plasma with and without the PAR1 antagonists SCH-79797 or BMS-200261. In concentrations previously shown to have activity on brain cells, neither drug showed evidence of protection against the toxicity of blood plasma. Newborn mice (wild type, heterozygous, and PAR1 knockout) were subjected to intracerebral injection of autologous whole blood into the periventricular region of the frontal lobe. Cell proliferation, measured by Ki67 immunoreactivity in the subventricular zone, was suppressed at 1 and 2 days, and was not normalized in the knockout mice. Cell apoptosis, measured by activated caspase 3 immunoreactivity, was not apparent in the subventricular zone. Increased apoptosis in periventricular striatal cells was not normalized in the knockout mice.

Conclusion: Interference with the thrombin-PAR1 system does not reduce the adverse effects of blood on germinal cells of the immature rodent brain. PAR1 interference is unlikely to be a useful treatment for reducing the brain damage that accompanies periventricular (germinal matrix) hemorrhage, a common complication of premature birth.
\end{abstract}

Keywords: Prematurity, Brain hemorrhage, Subventricular zone, Thrombin receptor, Coagulation factor II receptor, Cell proliferation

\section{Background}

Hemorrhage in the periventricular germinal tissue of developing brain (often called germinal matrix or periventricular hemorrhage, $\mathrm{PVH}$ ) is a major complication of preterm birth before 32 weeks gestational age [1]. $\mathrm{PVH}$ is associated with suppressed proliferation of the periventricular germinal cell populations in human infants [2]. The same suppression occurs in an experimental mouse model [3]. It is important to understand this

\footnotetext{
*Correspondence: marc.delbigio@umanitoba.ca
Department of Pathology, University of Manitoba, and Children's Hospital

* Correspondence: marc.delbigio@umanitoba.ca
Department of Pathology, University of Manitoba, and Children's Hospital Research Institute of Manitoba, 401 Brodie Centre, 715 McDermot Avenue, Winnipeg, MB R3E 3P5, Canada
}

phenomenon because it may adversely affect subsequent brain development and contribute to the neurological complications suffered by premature infants [4]. Blood injections have been shown to damage immature mouse brain; much of the effect seems to be attributable to the plasma proteins thrombin and plasmin $[5,6]$. Using cultured rat subventricular zone (SVZ) cells and oligodendrocyte precursor cells (OPC) we showed that blood plasma and blood serum, as well as purified thrombin, plasmin, and kallikrein had similar toxic effects on cell proliferation, migration, and differentiation [7].

Prothrombin is a serine protease contained in blood plasma. Following activation, thrombin has a central in 
the blood coagulation cascade. It also promotes inflammation and acts as a mitogen for some cell types [8]. In adult animal models of brain hemorrhage, thrombin plays a role in the resulting brain damage [9]. Signaling through one of the major G-protein coupled receptors, protease activated receptor 1 (PAR1; properly called coagulation factor II receptor, F2r), appears to mediate the process $[10,11]$. Interference with this pathway has been proposed as a potential target for therapeutic intervention following brain hemorrhage. Following blood injection into 1-day-old mouse brains, the thrombin inhibitor hirudin was capable of reducing inflammation and brain cell death at 2 days, but the long-term outcomes were unchanged [6]. In the rat brain cell model system, hirudin reduced the cell death caused by thrombin but not the suppression of cell proliferation [7]. Plasmin, which was shown to be damaging in the above-mentioned mouse and cell culture models, can also act through PAR1 [12].

Cultured OPC express high levels of PAR1 messenger RNA with expression declining as the cells mature, and they show PAR1 and PAR2 immunoreactivity at the O4+ stage of maturation [13]. Cultured OLN-93 oligodendrocyte cells also express PAR1 and PAR3, but not PAR2 or PAR4 [14]. Thrombin stimulation causes increases in intracellular calcium ion in SVZ-derived OPC and the effect is mediated by PAR-1 activation [15]. SCH-79797 suppresses PAR1 signaling in primary astrocyte cultures $[16,17]$ and in hippocampal slice cultures [18] and it protects against brain injury in rats [19]. BMS-200261 interferes with PAR1 in cultured astrocytes [12] and reduced infarct volume in a mouse model of focal cerebral ischemia [20]. We hypothesized that interference with the PAR1 will reduce the germinal cell damage associated with blood injection into the immature rodent brain. The first aim was to determine if chemical PAR1 antagonists could reduce damage to cultured mouse and rat OPC exposed to blood plasma. The second aim was to compare periventricular SVZ damage following blood injection into brains of newborn wild type, heterozygote, and PAR1 knockout mice. In mice this region rapidly involutes between birth and 8 days age [21]. Cells born here are destined to become oligodendrocytes and astrocytes in the cerebrum and neurons in the olfactory bulb [22-25].

\section{Results}

OPC cultures exposed to blood plasma and PAR1 inhibitors

Both the rat and mouse OPC cultures expressed predominantly oligodendrocyte lineage markers, including A2B5 at 6 hours, O4 for up to 3 days, and CNPase and MBP after 6 days. In the absence of plasma, exposure of rat $\mathrm{OPC}$ to $\mathrm{SCH}-79797$ at concentrations of 0.05 to $5 \mu \mathrm{M}$ had no obvious affect on LDH release, while 10$50 \mu \mathrm{M}$ was associated with a 2 -fold increase in LDH release $(\mathrm{P}<0.05)$. In the absence of plasma, exposure of rat OPC to BMS-200261 at 0.05 to $50 \mu \mathrm{M}$ had no obvious affect on LDH release, $100 \mu \mathrm{M}$ was associated with a 2-fold increase in LDH release, and $200 \mu \mathrm{M}$ was associated with a 4 -fold increase in LDH release $(\mathrm{p}<0.05$; Figure 1). Exposure of rat OPC to plasma at 1:1000 concentration was associated with a 2-fold increase in LDH release, 1:250 was associated with a 3.5-fold increase in LDH release, and 1:100 was associated with a 6-fold increase in LDH release. Combined with plasma at 1:1000, 1:250, or 1:100 concentrations, SCH-79797 showed no evidence of protection at 0.05-5 $\mu \mathrm{M}$ concentrations. Combined with plasma at 1:250 concentration, 10-50 $\mu \mathrm{M}$ SCH-79797 accentuated the toxicity (4-fold increase in LDH release). Combined with plasma at 1:250 concentration, BMS-200261 showed no evidence of protection at 0.05-10 $\mu \mathrm{M}$ while $25-200 \mu \mathrm{M}$ accentuated the toxicity (4-fold increase in LDH release) (Figure 2). Cell proliferation measured by BrdU incorporation was not normalized with the drug therapy (all comparisons $\mathrm{p}>0.5$ ).

The mouse OPC experiment was abbreviated with avoidance of the high concentrations of drug that were independently toxic to the rat OPC. Exposure to blood plasma at 1:250 concentration was associated with a 5 -fold increase in LDH release from mouse OPC. Exposure of mouse OPC to SCH-79797 at 5-10 $\mu \mathrm{M}$ caused a slight increase in LDH release; combined with plasma at 1:250 the toxic effect was doubled (10-fold increase LDH release). Exposure of mouse OPC to plasma at 1:250 concentration combined with BMS-200261 at 0.5 and $2 \mu \mathrm{M}$ reduced the LDH release in comparison to plasma alone, however the difference was not statistically significant (194 \pm 88 vs. $51 \pm 18 \mathrm{U}$; $\mathrm{p}=0.22$ ).

\section{$\mathrm{PAR}^{-/-}$mice with autologous blood injection into brain}

Blood injected mice suffered no mortality and there was no obvious behavioral consequence. In intact and sham injected control mice (wild type, heterozygote, and PAR1 ${ }^{-/}$), Ki67 was expressed by $23.5 \pm 4.8 \%$ of SVZ cells along the frontal horns of the lateral ventricles. There were no significant differences between the controls at the two time points or between genotype. Only scattered cells outside of the SVZ were Ki67 positive. In the controls, activated caspase 3 immunoreactivity was negligible. Microglia with delicate processes that expressed Iba1 were scattered throughout the cerebrum. However, within the SVZ only a small proportion $(1.4 \pm 0.2 \%)$ of cells expressed Iba1. There were no statistically significant differences across genotype or time (all $\mathrm{p}>0.4$ ).

Following blood injection into the right periventricular region, blood entered the frontal horns of the lateral ventricles, which enlarged slightly. Ki67 expression by proliferating cells decreased in the ipsilateral SVZ. In comparison to controls, the differences were statistically 


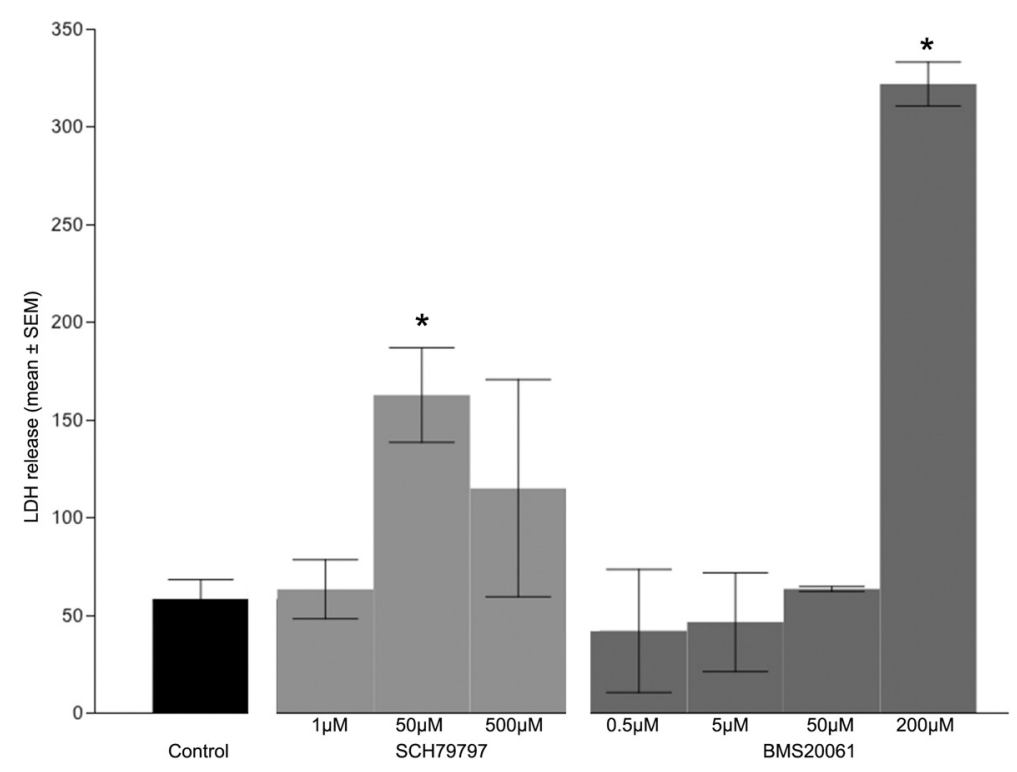

Figure 1 Bar graph showing effects of PAR1 inhibitors on rat oligodendrocyte precursor cells (OPC) cultured in serum-free defined media. Cell death was measured by LDH release (optical density units; mean \pm SEM). At high concentrations both SCH79797 and BMS20061 were toxic to the cells $\left({ }^{*} p<0.05\right)$.

significant for the 24-hour heterozygous and the 48hour wild type mice $(\mathrm{p}<0.005$; Figure $3 \mathrm{~A}-\mathrm{C})$. Following blood injection, suppressed Ki67 expression in the $\mathrm{PAR}^{-1-}$ mice with did not differ from the wild type or heterozygous mice at either time point $(\mathrm{p}=0.40$ to $0.95)$. In the contralateral SVZ the only significant difference in Ki67 expression after blood injection was a slightly lower percentage in the PAR $1^{-/-}$mice at 24 hours $(19.3 \pm 2.5 \%$ vs. $28.4 \pm 5.8 \%$ in heterozygote control, $\mathrm{p}=0.0418 ; 26.6 \pm 3.1 \%$ in wild type control, $\mathrm{p}=0.136$ ); at 48 hours there were no differences between groups ( $\mathrm{p}>0.7)$.

In comparison to mice without blood injection, activated caspase 3 immunoreactive cells were significantly increased in the heterozygous mice at 24 hours (and the wild type mice at 48 hours after blood injection (Figure 4A-C). Careful evaluation of the H\&E stained sections demonstrated only very rare karyorrhectic

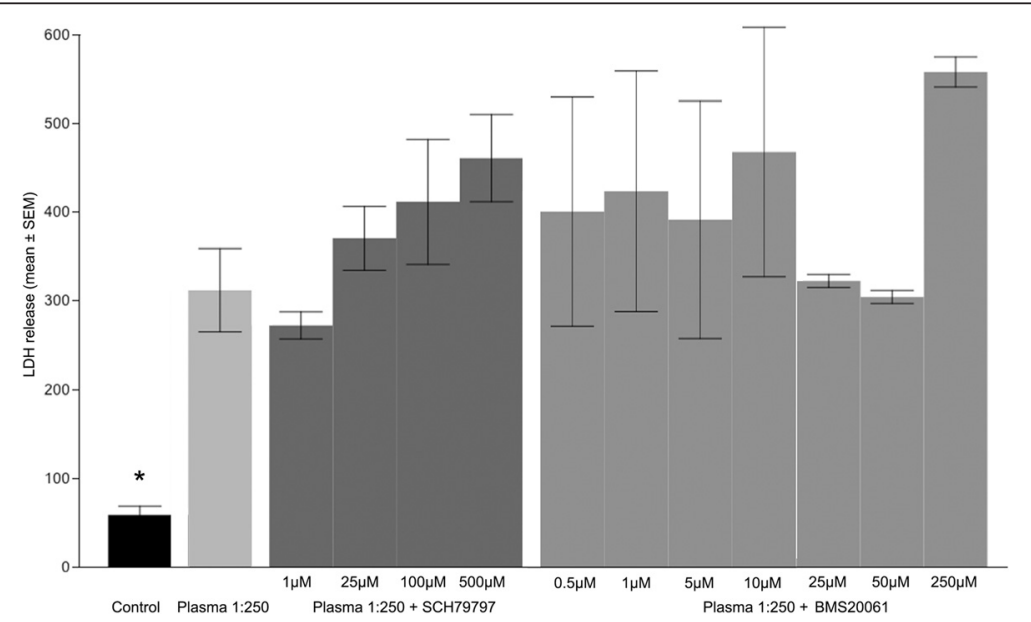

Figure 2 Bar graph showing effects of plasma alone and in combination with PAR1 inhibitors on rat oligodendrocyte precursor cells (OPC) in culture. Cell death was measured by LDH release (optical density units; mean \pm SEM). Plasma at 1/250 concentration added to the defined culture media was toxic to OPC as indicated by increased LDH release. There was no evidence for protection with SCH79797 and BMS20061 at any dose. Control values (no plasma) were significantly less than all groups $\left({ }^{*} p<0.05\right)$ and there were no statistically significant differences between treatment groups (all comparisons $p>0.5$ ). 

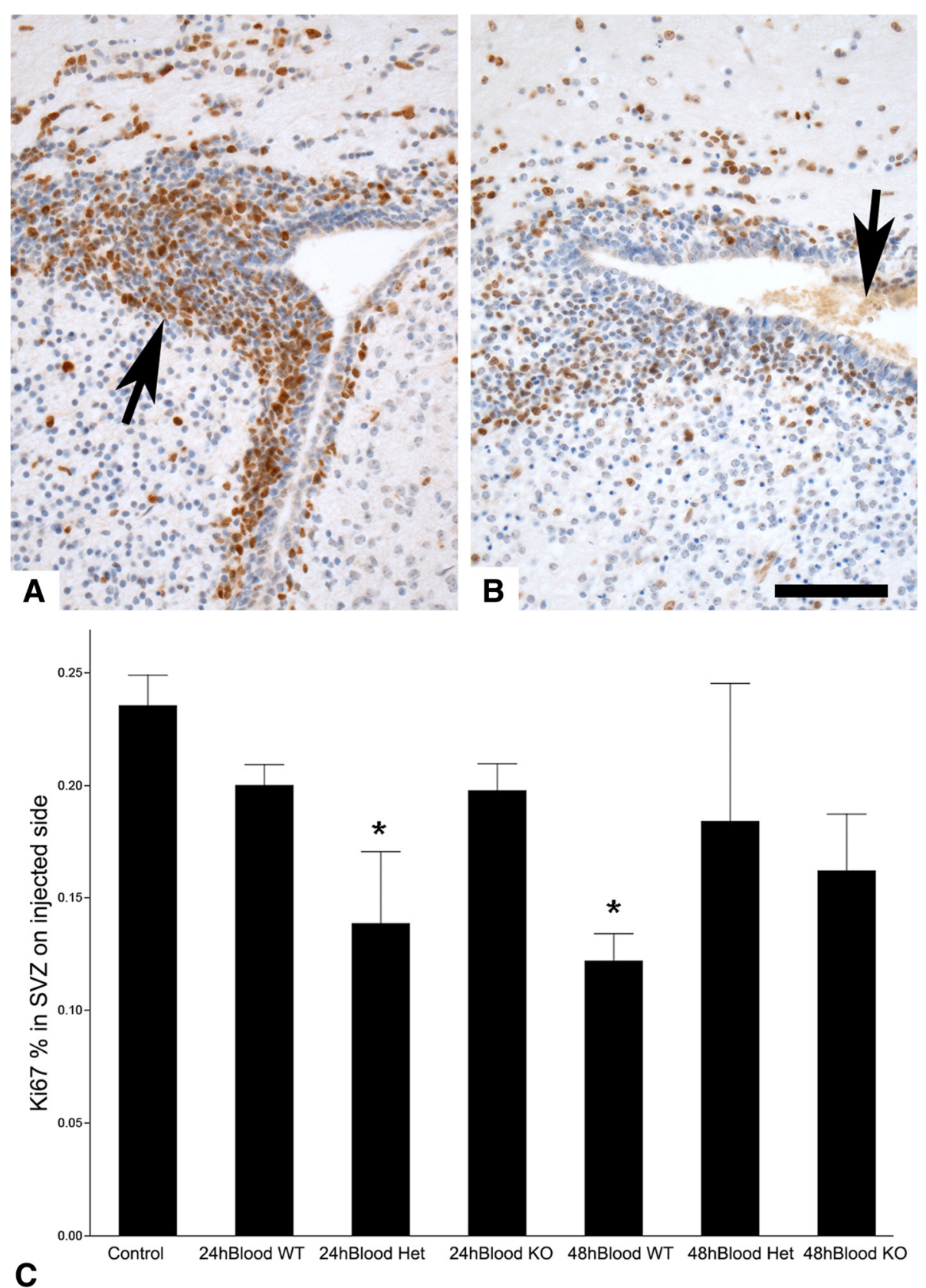

Figure 3 Cell proliferation in immature mouse brain following periventricular blood injection. A - Ki67 nuclear immunoreactivity (brown stained nuclei; hematoxylin counterstain) is prominent in the frontal periventricular subventricular zone (SVZ, arrow) of control (i.e. no blood injection) mice from all three genotypes (this example is wild type). B - Following blood injection, some of which extends into the frontal horn of the lateral ventricle (arrow), Ki67 immunoreactivity in the SVZ is reduced (this example is a PAR1 knockout). C - Quantitative analysis (ANOVA) shows the proportion of Ki67 immunoreactive cells in the SVZ was significantly reduced in the 24-hour heterozygous (Het; $\left.{ }^{*} p=0.0050\right)$ and the 48-hour wild type $\left(\mathrm{WT}^{*}{ }^{*} \mathrm{p}=0.0054\right)$ mice; the reduction also approached significance in the 48-hour knockout $(\mathrm{KO} ; \mathrm{p}=0.0577)$ in comparison to controls. Bar $=100 \mu \mathrm{m}$.

nuclei. Most (>80\%) immunoreactive cells were in the striatum and very few were in the SVZ. This is similar to our previous observation in mice that blood injection substantially suppresses SVZ proliferation but has only minor effects on cell death [3]. The PAR $1^{-1-}$ mice with blood injection did not differ from controls that had not received blood injection, and they had significantly fewer caspase 3 positive cells in the periventricular striatum (but not SVZ) at 48 hours in comparison to bloodinjected wild type mice $(\mathrm{p}=0.0028)$. The general trends 

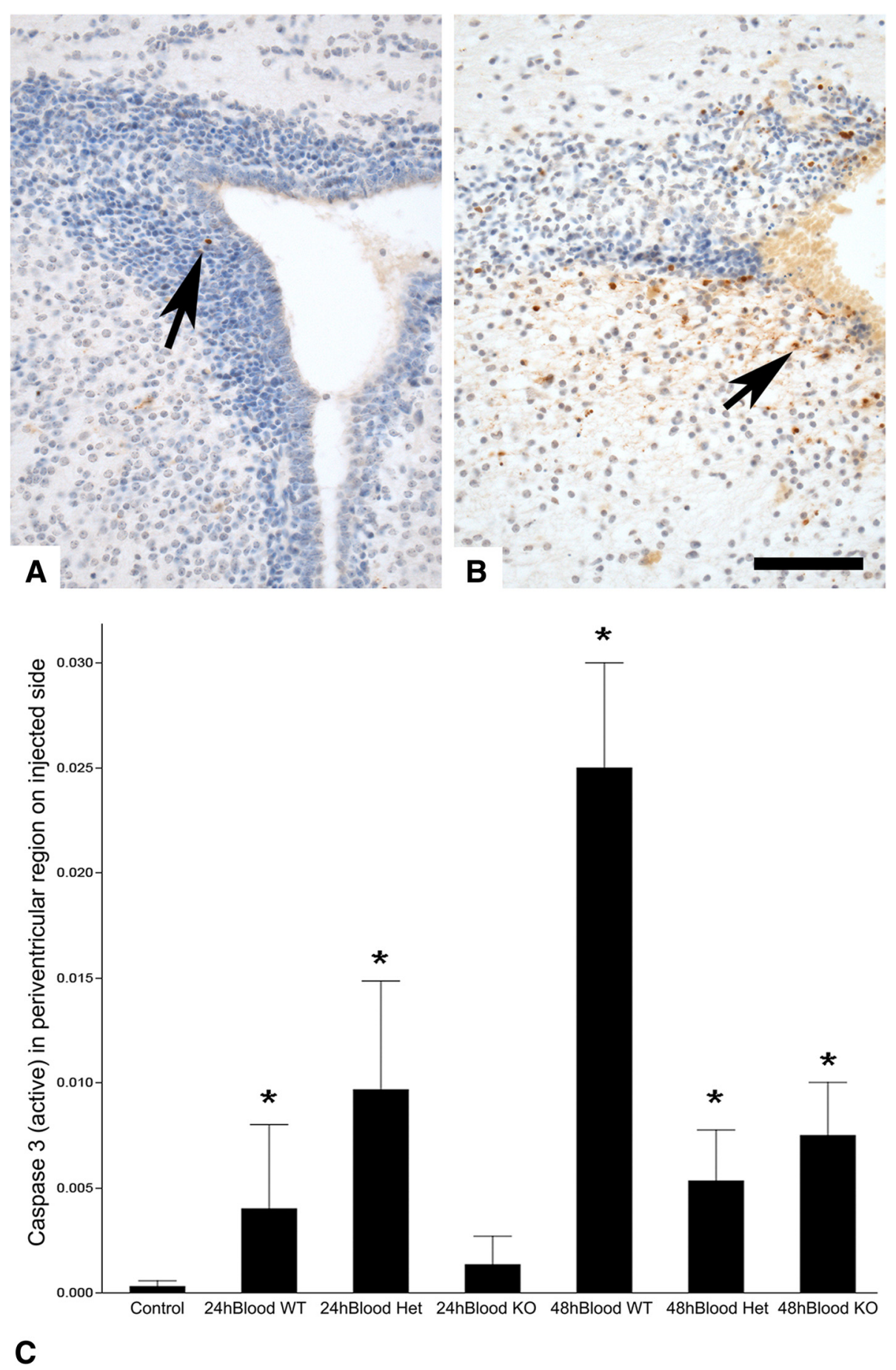

Figure 4 Cell death in immature mouse brain following periventricular blood injection. A - Activated caspase 3 immunoreactivity is extremely rare in the SVZ of control mice (brown stained cells; hematoxylin counterstain) (arrow; this example is wild type). B - Following blood injection, activated caspase 3 immunoreactivity is prominent in the striatum (arrow) but very rare in the SVZ (this example is a PAR1 knockout). C - Quantitative analysis shows a statistically significant increase in caspase 3 immunoreactive cells in the striatum of most groups in comparison to intact control $(p<0.007)$, but there were no significant differences between the blood-injected groups (all $p>0.15$; Wilcoxon method). All micrographs were taken at $400 \times$ magnification. Bar $=100 \mu \mathrm{m}$. 
were similar for activated caspase 3 positive in the cerebral white matter, but none of the differences were statistically significant (all $\mathrm{p}>0.2$ ).

Following blood injection, the quantity of Iba1 expressing cells in the SVZ was significantly lower in most groups in comparison to intact baseline (e.g. $0.6 \pm 0.2 \%$ in $48 \mathrm{~h}$ blood-injected heterozygote vs. $1.4 \pm 0.2 \%$ in intact control; $\mathrm{p}=0.0326$ ). However, there were no differences between genotypes following blood injections (all comparisons $>0.13$ ) and considering the very low baseline values it is not clear that the decrease after blood injection is biologically important. There was no numeric change in the cerebral white matter following blood injection in any group. However, the immunoreactive cells tended to be larger suggesting that the microglia had reacted to the needle insertion and/or blood injection.

\section{Discussion}

Blood, blood plasma, blood serum, plasmin, and thrombin were previously shown in our laboratory to suppress proliferation and cause cell death in rat OPC in a dosedependent manner [7]. Neonatal mouse brain showed comparable sensitivity in vivo following injection of blood components including suppressed cell proliferation in the SVZ $[3,5,6]$. PAR1 has repeatedly been shown to play an important role in hemorrhagic brain damage in adult experimental models [9,10,26,27]. However, based on the experiments presented here, we reject the hypothesis that PAR1-mediated signaling is critical to the SVZ changes that follow brain hemorrhage. Blood plasma was applied to OPC at a concentration previously shown to cause a combination of reduced cell proliferation and increased cell death [7]. At concentrations previously shown to have activity in astrocytes [12,17] and hippocampal slices [18], the selective peptide (BMS200261) and nonpeptide (SCH-79797) inhibitors of the PAR1 receptor failed to protect mouse or rat OPCs against the toxic effect of blood plasma, despite the fact that these cells are known to express PAR1 and respond to its activation $[13,15]$. The chemicals used have both been shown to suppress PAR1 signaling in cultured brain cells $[12,16,17]$ and to protect against brain injury in adult rodents $[19,20]$. At high concentrations the PAR1 inhibitors themselves were toxic. SCH-79797 (200 nM) has been shown to cause apoptosis in 3 T3 fibroblast cell cultures through PAR1 independent mechanisms [28]. One likely reason why the PAR1 inhibitors were not protective is the fact that blood plasma contains many other injurious constituents that act through non-PAR1 mediated mechanisms. We have previously shown in this OPC culture model, that cells are also suppressed and killed by complement 5a, gamma amino butyric acid, and kallikrein [7].

In the neonatal mouse experiment, injection of autologous blood into the periventricular region of the brain caused a substantial suppression of proliferating SVZ cells as well as a slight increase in apoptosis among nonSVZ periventricular cell populations. This is similar to the findings in our previous experiments using this model system $[3,5]$. In the current experiment, the damaging effect of blood on the periventricular SVZ was not modified through selective omission of the thrombin receptor PAR1. However, there was a decrease in caspase 3 activation (presumably an indicator of apoptosis) within the striatum, where the cells are more mature. Adult PAR $1^{-1-}$ mice have less brain damage following intracerebral injection of thrombin [10], transient occlusion of the middle cerebral artery [20,29], global ischemia [30], and following cortical stab injury [26]. The absence of a protective effect on SVZ cells in vivo might also relate to the distribution of PAR1 in the developing brain. During mouse development, PAR1 plays an important role in vasculogenesis and hemostasis [31], as well as more focal involvement in neural tube closure [32]. Reports on expression of PAR1 mRNA in developing rodent brain are not entirely consistent. In one mouse brain database, PAR1 is expressed mainly on endothelial cells and a subpopulation of SVZ cells on gestational day 15, while on postnatal day 7 most PAR1 expression is in neurons [33]. In another mouse database, ganglionic eminence progenitors are reported to have high expression on gestational day 16 [34]. In the rat, PAR1 mRNA is abundant in the periventricular region of brain at gestational day 14 and the day of birth, while discrete neuronal expression is predominant by postnatal day 7 [35].

Shortcomings must be considered. Despite the value of mouse experiments for genetic manipulation, newborn mouse is not the ideal animal model for studying germinal matrix damage following PVH. In humans, premature birth at 24-28 weeks gestation is the period of greatest risk for PVH [1]. In some respects the postnatal day 6-7 mouse brain is comparable to human brain at that stage of development [36]. However, in terms of relative volume, the ganglionic eminence (the largest SVZ concentration) of the gestational day 17 mouse and gestational week 24 human are more comparable $[2,21]$. Furthermore, the mouse SVZ is much less complex than in primates $[37,38]$. The proportion of proliferating cells in the human ganglionic eminence SVZ at 24 weeks gestation is approximately $60 \%$ [2]. In neonatal mice the proportion is much lower at $\sim 23 \%$. We focussed on PAR1 because most experimental evidence shows a role for that receptor in brain damage related to hemorrhage. However, PAR2 [39], PAR3 [40], and PAR4 [41] also appear to play roles in microglial activation and neuron degeneration that follow experimental brain injury. Small sample sizes must be considered. In the OPC culture experiments, toxicity of the PAR1 
inhibitors was not strictly dose dependent suggesting some unexplained variation in the system. However, the inhibitors showed no trends suggesting protection. Despite small sample sizes in the mouse experiment the basic cellular responses to blood injection (reduced SVZ proliferation, increased cell death in the adjacent striatum) were in the predicted directions and there were no trends suggesting that the PAR1 knockouts had any reduced damage in the SVZ. Failing to identify any positive effects in two kinds of experiments, analysis of PAR1 role in these model systems was not exhaustive, however rejection of the hypothesis is reasonable.

\section{Conclusions}

We conclude that blocking the thrombin-PAR1 system does not reduce the adverse effect of blood and blood plasma on SVZ cells and OPC of the developing rodent brain, despite the published evidence for expression and functionality of PAR1 in these cell populations. These experiments might not exclude an important role of thrombin, but they do show that thrombin-induced damage through PAR1 is not the exclusive mode of injury following exposure to blood plasma, which contains many active and potentially toxic proteins and catabolic products [42]. Despite published evidence in adult model systems, protection of immature brain against the adverse effects of hemorrhage by interference of a single molecular pathway should be considered unlikely.

\section{Methods}

\section{Reagents}

Dulbecco's Modified Eagle's Medium (DMEM), poly-Dlysine (PDL), putrescine, thyroxin, tri-iodothyroxine, progesterone, sodium selenite, papain, deoxyribonuclease l, bovine serum albumin (BSA) fraction V, and insulin were purchased from Sigma-Aldrich. L-glutamine, $0.25 \%$ trypsin-EDTA, and fetal bovine serum (FBS) were purchased from Invitrogen/Life Technologies. MEM was purchased from Gibco/Life Technologies. Holo-transferrin (human) was purchased from EMD Millipore. Trypsin inhibitor was purchased from Roche Life Science. FGF-basic and EGF were purchased from Peprotech. PDGF-AA was purchased from R\&D Systems Inc.

\section{Animals}

All experiments were approved by the University of Manitoba Animal Care Committee. Sprague-Dawley rats and wild type $\mathrm{C} 57 \mathrm{BL} / 6$ mice were bred at the Central Animal Care facility of the University of Manitoba. Heterozygous PAR1 knockout mice (B6.129S4-F2r ${ }^{t m 1 A j c} / \mathrm{J}$ ) on a $\mathrm{C} 57 \mathrm{Bl} / 6$ background were purchased from Jackson Laboratories (Stock Number: 002862). Animals were bred to obtain homozygous PAR1 knockout mice. The genotype of newborn mice was determined from tail samples.
Genomic DNA was extracted using proteinase $\mathrm{K}$ in a DNA digestion buffer. Polymerase chain reaction (PCR) was used to detect PAR1 using the specific primers 5'GAC GTT CAG AGG AAG GCT GA3' (oIMR3504, Wild type), 5' AAA ATG AAA GCG TCC TGC TG3' (oIMR3503, Common) and 5'TGG ATG TGG AAT GTG TGC GAG3' (oIMR8162, Mutant). PCR products were separated by electrophoresis in a $2 \%$ agarose gel and stained with Gelstar Nucleic Gel stain. The expected bands are wild type $=175$ base pairs (bp), mutant $=225 \mathrm{bp}$, and heterozygote $=175 \mathrm{bp} / 225 \mathrm{bp}$.

\section{Cultures of rat and mouse oligodendrocyte precursor cells (OPC)}

Rat OPC were cultured as previously described in detail [7]. Mouse OPC cultures required some modifications [43]. Wild-type mice were decapitated at 1-day age, the brain was removed and stripped of meninges, the cerebral hemispheres (excluding hippocampus and basal nuclei) were isolated, and cells were dissociated in DMEM medium supplemented with 5000U penicillin and streptomycin and Accutase cell detachment solution (Millipore). Cells were washed and resuspended in DMEM culture medium supplemented with $4 \mathrm{mM}$ L-glutamine, $5000 \mathrm{U}$ penicillin and streptomycin, $20 \%$ heat inactivated fetal bovine serum (FBS), $10 \mathrm{ng} / \mathrm{ml}$ basic fibroblast growth factor (bFGF), $10 \mathrm{ng} / \mathrm{ml}$ epidermal growth factor (EGF) and $5 \mathrm{ng} / \mathrm{ml}$ of platelet-derived growth factor (PDGF-AA) then grown in lysine-coated flasks. On day 7-8, DMEM medium with L-glutamine, penicillin and streptomycin, $20 \% \mathrm{FBS}$, and $10 \mathrm{ng} / \mathrm{ml}$ PDGF was used. Cultures were kept at $37^{\circ} \mathrm{C}$ in humidified chamber with $5 \% \mathrm{CO}_{2}$; the media was changed every 3-4 days. OPCs were isolated from the mixed glial culture by shaking on day 14-18. Microglia were removed by allowing them to attach in a plastic Petri dish. Floating OPCs were cultured on glass coverslips in Sato's serum-free modified medium, which contained 20 ng/ml PDGF-AA, putrescine (Sigma P5780) $0.16 \mu \mathrm{g} / \mathrm{ml}$, thyroxin (T4, Sigma T-1775) $4 \mathrm{ng} / \mathrm{ml}$, triiodothyroxine (T3, Sigma T-6397) $4 \mathrm{ng} / \mathrm{ml}$, progesterone (Sigma P8783) $0.66 \mathrm{ng} / \mathrm{ml}$, bovine serum albumin (BSA) fraction V (Sigma A4919) $1 \mu \mathrm{g} / \mathrm{ml}$, L-glutamine (GIBCO), human holotransferrin (Sigma T0665), Penstrep (Invitrogen 15140), and insulin (Sigma I1882). In pilot experiments (results not shown), oligodendrocyte lineage was verified after 6 hours, 3 days, and 6 days by fixing cells in cold methanol and $4 \%$ paraformaldehyde, followed by immunofluorescence using primary antibodies to A2B5 (mouse IgM; Millipore MAB312R), myelin basic protein (MBP, rabbit IgG; Santa Cruz SC-13914), 2'3'cyclic-nucleotide 3'-phosphodiesterase (CNPase, mouse IgG; Millipore MAB326), O4 (mouse IgM; Neuromics MO15002), and glial fibrillary acidic protein (to exclude astrocytes, rabbit IgG; Novocastra Z0334) and appropriate 
secondary antibodies with 4',6-diamidino-2-phenylindole (DAPI; Sigma, D-8417) labeling of nuclei.

\section{Cultured oligodendrocyte precursor cell (OPC) cell death assays}

We previously showed that plasma at 1:100 dilution had a negative effect on OPC proliferation and caused cell death detectable by both lactate dehydrogenase (LDH) release and activation of caspase 3. Purified thrombin at the calculated equivalent dose had a slightly greater (although not statistically significant) adverse effect [7]. Adult mouse and rat blood were collected in EDTAcoated tubes (to prevent blood clotting) and plasma was isolated as previously described [7], then aliquoted and stored at $-20^{\circ} \mathrm{C}$. When the thawed plasma is added to $\mathrm{Ca}^{++}$-containing cell culture medium plasma enzyme activity is normalized [44], although fibrinogen activity might not be entirely restored [45]. Isolated OPCs from rat and wild type C57Bl6 mice in serum-free Sato's culture medium were plated in 24-well plates with PDLcoated glass coverslips $\left(1 \times 10^{5}\right.$ or $2 \times 10^{5}$ cells/well in different trials) and allowed to adhere. Four hours later the media was changed to serum-free Sato's medium with added $10 \mu \mathrm{M}$ bromodeoxyuridine (BrdU Sigma B-5002) with or without added PAR1 antagonists SCH-79797 dihydrochloride (Tocris, Ellisville, MO, USA) or BMS200261 (Sigma). The dose range was based on previously published work. SCH-79797 modulated the response of cultured astrocytes to plasmin at a concentration of $5 \mu \mathrm{M}$ [17] and thrombin-mediated cell death in hippocampal slices at $10 \mu \mathrm{M}$ [18]. BMS-200261 blocked the plasmin-induced rise of cytoplasmic $\mathrm{Ca} 2+$ in cultured astrocytes at $1 \mu \mathrm{M}$ [12], The cells were simultaneously exposed to rat or mouse blood plasma (1:100, 1:250, and 1:1000 dilutions) for $24 \mathrm{~h}$. Incorporated BrdU was detected with monoclonal mouse anti-BrdU antibody (Cell Signaling\# 5292) and cells were counterstained with DAPI. Cells were counted with a fluorescence microscope using a 20x objective magnification. Prior to fixation, $5 \mu \mathrm{l}$ supernatant from OPC cultures was transferred to a 96-well plate, and $50 \mu \mathrm{l}$ of the LDH cytotoxicity detection kit II (Biovision) reaction mixture was added. After 30 minutes absorbance was recorded at $450 \mathrm{~nm}$ using microplate reader. LDH concentration was calculated in triplicate according to standards with background subtraction. All rat OPC tests were repeated in triplicate from separate cell isolations and all results were read at 30 minutes and 3 hours. All mouse OPC tests were done in duplicate. Data, expressed as mean \pm standard error of mean, were compared using ANOVA.

Autologous blood injection into neonatal mouse cerebrum PAR1 mutant heterozygote mice mating typically yielded 2-3 neonates of each genotype $\left(\mathrm{PAR} 1^{-/-}, \mathrm{PAR} 1^{+/-}\right.$,
$\mathrm{PAR}^{+/+}$) per litter. Mice were housed with their mothers. As previously described [3,6], 1-day-old mice were anesthetized with $2 \%$ isoflurane, whole blood was obtained from the tail and then was injected ( $15 \mu \mathrm{l}$ though a 30 gauge needle) into the right periventricular region/ striatum. The injection coordinates were $1.5 \mathrm{~mm}$ lateral to midline, $0.5 \mathrm{~mm}$ posterior to the outer canthus of the eye, and $2.5 \mathrm{~mm}$ depth. Syringes contained no anticoagulants and procedures were completed within 2 minutes before the blood clotted. We previously showed that serine protease activity due to thrombin and/or plasmin is elevated at the edge of the resulting hematoma [6]. Additional controls included sham injected and intact brain of all genotypes. Mice were killed by isoflurane overdose followed by exsanguination and transcardiac perfusion with cold $4 \%$ paraformaldehyde in phosphate buffered saline 24 or 48 hours after blood injection. The brains were removed, left overnight in the same fixative, sliced in the coronal plane encompassing the blood injection site, dehydrated, and embedded in paraffin. Brains were assessed at 24 and 48 hours after blood injection ( 3 genotypes $\times 2$ time points $\times 2$ conditions; 3-4 per group).

Brain slices were sectioned serially at $5 \mu \mathrm{m}$ thickness and every 10th slide was stained with hematoxylin and eosin (H\&E) to identify the center of the injection site. In previous similar experiments we determined in advance several exclusion criteria to be determined by microscopic examination: 1) sham injections with blood occupying the striatum or ventricle; 2) blood injections with no obvious blood collections or hematoma not involving the SVZ. In this experiment no exclusions were mandated. Deparaffinized sections were treated using heat-mediated antigen retrieval $(0.1 \mathrm{M}$ citrate buffer, pH6, for 20 minutes) and endogenous peroxidase was suppressed with $3 \% \mathrm{H}_{2} \mathrm{O}_{2}$ in methanol for 10 minutes. Sections were blocked with $10 \%$ goat serum in PBS. Immunohistochemical staining was used to detect reactive astrocytes (rabbit anti-GFAP, 1:3000; Novocastra Z0334), proliferating cells (rabbit anti-Ki67, 1:2000; Novocastra Labs NCL 301103), and apoptotic cells (rabbit antiactivated caspase-3, 1:250; Gene Tex GTX22302). Microglia were detected with rabbit anti-Iba1 (1:2000; Wako, Osaka, Japan 019-19741), and reactive changes were evaluated by cell hypertrophy and increased cell density in comparison to the contralateral side. Immunoreactive cells were revealed using biotinylated goat antirabbit secondary (Jackson IR, 111-065-144) followed by streptavidin/horseradish peroxidase (HRP; Jackson IR 016-030-084), and diaminobenzidine (DAB with $10 \mu \mathrm{L}$ $\left.30 \% \mathrm{H}_{2} \mathrm{O}_{2}\right)$. After hematoxylin counterstain, sections were dehydrated and coverslipped.

The evaluator was blinded to the genotype. Immunoreactive cells and total cells were counted at 400x 
magnification in two anatomical regions bilaterally (ipsiand contralateral to the injection site) using an ocular counting grid. The subventricular zone (SVZ) between the frontal horn of the lateral ventricle and the striatum and at the angle of the frontal horn was evaluated in a $50 \times 200 \mu \mathrm{m}$ rectangle and an approximately $200 \times 200 \mu \mathrm{m}$ triangular area. Dorsal white matter above the ventricle was evaluated in a $150 \times 500 \mu \mathrm{m}$ rectangular area. The number of cells immunoreactive for each antigen was calculated and the means were compared. For the Ki67, which had a normal distribution, we used ANOVA followed by Dunnett's method for comparison to controls without blood injection and Tukey-Kramer tests for comparison to matched groups with blood injection. The caspase 3 and Iba1 values did not have normal distributions, therefore we used the nonparametric Wilcoxon method to compare groups (JMP10 software; SAS Institute, Cary NC). Differences were considered significantly different at $\mathrm{p}<0.05$.

\section{Abbreviations}

ANOVA: analysis of variance; CNPase: 2',3'-cyclic-nucleotide 3'-phosphodiesterase; DMEM: Dulbecco's Modified Eagle's Medium; LDH: Lactate dehydrogenase; MBP: Myelin basic protein; OPC: Oligodendrocyte precursor cell; PAR1: Protease activated receptor 1; PVH: Periventricular hemorrhage; SVZ: Subventricular zone.

\section{Competing interests}

The authors declare that they have no competing interests.

\section{Authors' contributions}

XM performed the experiments, collected the data, and wrote the initia draft of the manuscript. MRD conceived the study and contributed to its design, microscopic review, data analysis, and finalized the manuscript. Both authors read and approved the final manuscript.

\section{Acknowledgements}

This work was funded by a grant from the Heart and Stroke Foundation of Canada (Manitoba). Dr. Del Bigio holds the Canada Research Chair in Developmental Neuropathology.

Received: 17 July 2014 Accepted: 22 December 2014

Published online: 04 February 2015

\section{References}

1. Del Bigio MR. Hemorrhagic Lesions. In: Golden JA, Harding BN, editors. Developmental Neuropathology. Basel, Switzerland: International Society of Neuropathology Press; 2004. p. 150-5.

2. Del Bigio MR. Cell proliferation in human ganglionic eminence and suppression after prematurity-associated haemorrhage. Brain. 2011;134:1344-61.

3. Xue M, Balasubramaniam J, Buist RJ, Peeling J, Del Bigio MR. Periventricular/ intraventricular hemorrhage in neonatal mouse cerebrum. J Neuropathol Exp Neurol. 2003;62:1154-65.

4. Ballabh P. Intraventricular hemorrhage in premature infants: mechanism of disease. Pediatr Res. 2010;67:1-8.

5. Xue M, Del Bigio MR. Injections of blood, thrombin, and plasminogen more severely damage neonatal mouse brain than mature mouse brain. Brain Pathol. 2005;15:273-80.

6. Xue M, Balasubramaniam J, Parsons KA, Mclntyre IW, Peeling J, Del Bigio MR. Does thrombin play a role in the pathogenesis of brain damage after periventricular hemorrhage? Brain Pathol. 2005;15:241-9.

7. Juliet PA, Frost EE, Balasubramaniam J, Del Bigio MR. Toxic effect of blood components on perinatal rat subventricular zone cells and oligodendrocyte precursor cell proliferation, differentiation and migration in culture. J Neurochem. 2009;109:1285-99.
8. Siller-Matula JM, Schwameis M, Blann A, Mannhalter C, Jilma B. Thrombin as a multi-functional enzyme. Focus on in vitro and in vivo effects. Thromb Haemost. 2011;106:1020-33.

9. Babu R, Bagley JH, Di C, Friedman AH, Adamson C. Thrombin and hemin as central factors in the mechanisms of intracerebral hemorrhage-induced secondary brain injury and as potential targets for intervention. Neurosurg Focus. 2012;32:E8.

10. Cheng $Y, X i G$, Jin $H$, Keep RF, Feng J, Hua Y. Thrombin-induced cerebral hemorrhage: role of proteaseactivated receptor-1. Transl Stroke Res. 2014:5:472-5.

11. Coughlin SR. Thrombin signalling and protease-activated receptors. Nature. 2000:407:258-64.

12. Mannaioni G, Orr AG, Hamill CE, Yuan H, Pedone KH, McCoy KL, et al. Plasmin potentiates synaptic N-methyl-D-aspartate receptor function in hippocampal neurons through activation of protease-activated receptor-1. J Biol Chem. 2008;283:20600-11.

13. Burda JE, Radulovic M, Yoon H, Scarisbrick IA. Critical role for PAR1 in kallikrein 6-mediated oligodendrogliopathy. Glia. 2013;61:1456-70.

14. Wang Y, Richter-Landsberg C, Reiser G. Expression of protease-activated receptors (PARs) in OLN-93 oligodendroglial cells and mechanism of PAR-1-induced calcium signaling. Neuroscience. 2004;126:69-82.

15. Grade S, Agasse F, Bernardino L, Silva CG, Cortes L, Malva JO. Functional identification of neural stem cell-derived oligodendrocytes by means of calcium transients elicited by thrombin. Rejuvenation Res. 2010;13:27-37.

16. Wang Y, Luo W, Wartmann T, Halangk W, Sahin-Toth M, Reiser G. Mesotrypsin, a brain trypsin, activates selectively proteinase-activated receptor-1, but not proteinase-activated receptor-2, in rat astrocytes. J Neurochem. 2006;99:759-69.

17. Maeda S, Nakajima K, Tohyama Y, Kohsaka S. Characteristic response of astrocytes to plasminogen/plasmin to upregulate transforming growth factor beta 3 (TGFbeta3) production/secretion through proteinase-activated receptor-1 (PAR-1) and the downstream phosphatidylinositol 3-kinase (PI3K)-Akt/PKB signaling cascade. Brain Res. 2009;1305:1-13.

18. Thevenet J, Angelillo-Scherrer A, Price M, Hirt L. Coagulation factor Xa activates thrombin in ischemic neural tissue. J Neurochem. 2009;111:828-36.

19. Manaenko A, Sun X, Kim CH, Yan J, Ma Q, Zhang JH. PAR-1 antagonist SCH79797 ameliorates apoptosis following surgical brain injury through inhibition of ASK1-JNK in rats. Neurobiol Dis. 2013;50:13-20.

20. Junge CE, Sugawara T, Mannaioni G, Alagarsamy S, Conn PJ, Brat DJ, et al. The contribution of protease-activated receptor 1 to neuronal damage caused by transient focal cerebral ischemia. Proc Natl Acad Sci U S A. 2003;100:13019-24.

21. Sturrock RR, Smart IH. A morphological study of the mouse subependymal layer from embryonic life to old age. J Anat. 1980;130:391-415.

22. Smart I. The subependymal layer of the mouse brain and its cell production as shown by radioautography after thymidine-H3 injection. J Comp Neurol. 1961;116:325-47.

23. Marshall CA, Novitch BG, Goldman JE. Olig2 directs astrocyte and oligodendrocyte formation in postnatal subventricular zone cells. J Neurosci. 2005;25:7289-98

24. Jang ES, Goldman JE. Pax6 expression is sufficient to induce a neurogenic fate in glial progenitors of the neonatal subventricular zone. PLoS One. 2011;6:e20894.

25. Tramontin AD, Garcia-Verdugo JM, Lim DA, Alvarez-Buylla A. Postnatal development of radial glia and the ventricular zone (VZ): a continuum of the neural stem cell compartment. Cereb Cortex. 2003;13:580-7.

26. Nicole O, Goldshmidt A, Hamill CE, Sorensen SD, Sastre A, Lyuboslavsky P, et al. Activation of protease-activated receptor-1 triggers astrogliosis after brain injury. J Neurosci. 2005;25:4319-29.

27. Suo Z, Wu M, Ameenuddin S, Anderson HE, Zoloty JE, Citron BA, et al. Participation of protease-activated receptor- 1 in thrombin-induced microglial activation. J Neurochem. 2002;80:655-66.

28. Di Serio C, Pellerito S, Duarte M, Massi D, Naldini A, Cirino G, et al. Proteaseactivated receptor 1-selective antagonist SCH79797 inhibits cell proliferation and induces apoptosis by a protease-activated receptor 1-independent mechanism. Basic Clin Pharmacol Toxicol. 2007;101:63-9.

29. Hamill CE, Mannaioni G, Lyuboslavsky P, Sastre AA, Traynelis SF. Proteaseactivated receptor 1-dependent neuronal damage involves NMDA receptor function. Exp Neurol. 2009;217:136-46.

30. Wang J, Jin H, Hua Y, Keep RF, Xi G. Role of protease-activated receptor-1 in brain injury after experimental global cerebral ischemia. Stroke. 2012;43:2476-82. 
31. Griffin CT, Srinivasan $Y$, Zheng $Y W$, Huang W, Coughlin SR. A role for thrombin receptor signaling in endothelial cells during embryonic development. Science. 2001;293:1666-70.

32. Camerer E, Barker A, Duong DN, Ganesan R, Kataoka H, Cornelissen I, et al. Local protease signaling contributes to neural tube closure in the mouse embryo. Dev Cell. 2010;18:25-38.

33. The Gene Expression Nervous System Atlas (GENSAT) Project [http://www. gensat.org/about.jsp]

34. Shimogori T, Lee DA, Miranda-Angulo A, Yang $Y$, Wang $H$, Jiang $L$, et al. A genomic atlas of mouse hypothalamic development. Nat Neurosci. 2010;13:767-75

35. Niclou SP, Suidan HS, Pavlik A, Vejsada R, Monard D. Changes in the expression of protease-activated receptor 1 and protease nexin-1 mRNA during rat nervous system development and after nerve lesion. Eur J Neurosci. 1998;10:1590-607.

36. Clancy B, Darlington RB, Finlay BL. Translating developmental time across mammalian species. Neuroscience. 2001:105:7-17.

37. Cheung AF, Pollen AA, Tavare A, DeProto J, Molnar Z. Comparative aspects of cortical neurogenesis in vertebrates. J Anat. 2007;211:164-76.

38. Dehay C, Kennedy H. Cell-cycle control and cortical development. Nat Rev Neurosci. 2007;8:438-50.

39. Yoon H, Radulovic M, Wu J, Blaber SI, Blaber M, Fehlings MG, et al. Kallikrein 6 signals through PAR1 and PAR2 to promote neuron injury and exacerbate glutamate neurotoxicity. J Neurochem. 2013;127:283-98.

40. Guo H, Liu D, Gelbard H, Cheng T, Insalaco R, Fernandez JA, et al. Activated protein $\mathrm{C}$ prevents neuronal apoptosis via protease activated receptors 1 and 3. Neuron. 2004:41:563-72.

41. Suo Z, Wu M, Citron BA, Gao C, Festoff BW. Persistent protease-activated receptor 4 signaling mediates thrombin-induced microglial activation. J Biol Chem. 2003;278:31177-83.

42. Tammen H, Schulte I, Hess R, Menzel C, Kellmann M, Mohring T, et al. Peptidomic analysis of human blood specimens: comparison between plasma specimens and serum by differential peptide display. Proteomics. 2005;5:3414-22.

43. Armstrong RC. Isolation and characterization of immature oligodendrocyte lineage cells. Methods. 1998;16:282-92.

44. Perizzolo KE, Sullivan S, Waugh DF. Effects of calcium binding and of EDTA and CaEDTA on the clotting of bovine fibrinogen by thrombin. Arch Biochem Biophys. 1985:237:520-34.

45. Piccione G, Casella S, Giannetto C, Giudice E. Effect of storage conditions on prothrombin time, activated partial thromboplastin time and fibrinogen concentration on canine plasma samples. J Vet Sci. 2010;11:121-4.

\section{Submit your next manuscript to BioMed Central and take full advantage of:}

- Convenient online submission

- Thorough peer review

- No space constraints or color figure charges

- Immediate publication on acceptance

- Inclusion in PubMed, CAS, Scopus and Google Scholar

- Research which is freely available for redistribution 